Fisheries Bycatch Reduction within the Least-Cost Biodiversity Mitigation Hierarchy: Conservatory Offsets with An Application to Sea Turtles

\author{
by \\ Dale Squires \\ NOAA Fisheries, Southwest Fisheries Science Center \\ 8901 La Jolla Shores Drive, La Jolla, CA 92103 USA \\ Dale.Squires@noaa.gov \\ Tel: +1 858-546-7113, Fax: +1 858-546-7113 \\ Corresponding author \\ Victor Restrepo \\ International Seafood Sustainability Foundation \\ Madrid, Spain \\ VRestrepo@iss-foundation.org \\ Serge Garcia \\ IUCN-CEM Fisheries Expert Group \\ Rome, Italy \\ grcsgm@gmail.com \\ Peter Dutton \\ NOAA Fisheries, Southwest Fisheries Science Center \\ 8901 La Jolla Shores Drive, La Jolla, CA 92103 USA \\ Peter.Dutton@noaa.gov
}

February, 2018

Key words: fisheries, bycatch, sea turtles, biodiversity mitigation hierarchy, offsets, least-cost conservation 


\begin{abstract}
This paper considers fisheries bycatch reduction within the least-cost biodiversity impact mitigation hierarchy. It introduces conservatory offsets that are implemented earlier in the biodiversity impact mitigation hierarchy than conventional compensatory offsets used as instruments of last resort. The paper illustrates implementation in an on-going sea turtle conservation programme by the International Seafood Sustainability Foundation.
\end{abstract}

\title{
Highlights
}

- Bycatch reduction within the biodiversity impact mitigation hierarchy

- Least-cost (cost-effective) bycatch reduction

- Conservatory offsets used within first 3 steps of the mitigation hierarchy and not as last resort.

- Sea turtle conservatory offsets projects of International Seafood Sustainability Foundation 


\section{Fisheries Bycatch Reduction within the Least-Cost Biodiversity Mitigation Hierarchy: Conservatory Offsets with An Application to Sea Turtles}

\section{Introduction}

How should fisheries bycatch reduction be achieved? ${ }^{1}$ This paper discusses three concepts that address this issue. First, it places fisheries bycatch reduction within the least-cost biodiversity impact mitigation hierarchy (BIMH) to achieve the maximum bycatch impact reduction, especially when faced with budgetary limits. Second, this paper develops conservatory offsets, used off-site in the first three steps of the BIMH (unlike conventional compensatory offsets used in the last step), as a voluntary, incentive-based, least-cost, and off-site complement or substitute for other, on-site mitigation measures of the first three steps. They yield benefits ranging from partial recovery to over-recovery (above the baseline) of the stock or habitat depending upon scheme and context. Third, this paper posits incentive-based bycatch policy to price bycatch and alter consumer and producer behavior and decision-making to achieve costeffective bycatch reduction within and across BIMH steps and all bycatch reduction channels and create dynamic incentives for bycatch-reducing technological change. This paper illustrates these three propositions through fisheries examples.

The following sections discuss successively: least-cost BIMH; BIMH and compensation; conservatory offsets in fisheries; and conservatory offsets in sea turtle conservation.

\footnotetext{
${ }^{1}$ Bycatch may consist of: (1) target species of non-commercial or prohibited landing size, or of catch inadvertently taken above quota; (2) protected species (e.g. emblematic or under mandatory rebuilding), with contributions to biodiversity and ecosystem, but without market price; and (3) species constituting living habitat (e.g. corals, sponges, seagrass, kelp) the contribution of which to biodiversity and ecosystem is most often poorly known and underpriced or unpriced.
} 


\section{Least-Cost Biodiversity Impact Mitigation Hierarchy}

The BIMH $[1,2,21]$ provides an overarching conservation framework that can be used to achieve bycatch reduction, and more generally marine biodiversity conservation $[13,15,19$, 20]. Its application aims to: (1) avoid any impact, (2) minimize unavoidable impact, (3) restore biodiversity, in that order and as much as practicable, before considering (4) to compensate the residual impact, aiming at No Net Loss. ${ }^{2}$ The first three steps are conservatory and applied onsite. The fourth step is compensatory, applied off-site and on different albeit comparable ('like-for-like' or 'in-kind') biodiversity, and entails offsets.

Fisheries management is similar in function and approach to the BIMH conservatory steps (Figure 1): avoid and minimize overfishing on-site, and as appropriate restore/rebuild depleted stocks [20]. The BIMH, never referred to in fisheries, is used in practice. Nothing in the United Nations Law of the Sea Convention (LOSC) impedes fishery managers from simultaneously addressing the three steps even though, logically, stocks cannot be "restored" before having fallen below the maximum sustainable yield (MSY) level (No Net Loss equivalent).

\section{Figure 1 here}

Avoidance of bycatch is on-site and uses: (i) risk-based spatial and temporal planning of fishing, notably zoning, closed areas (including Marine Protected Areas) to protect habitats, nurseries, endangered species and biodiversity 'hotspots'; (ii) moratoria in the case of deep depletion; and (iii) bycatch-reducing technological innovation, e.g. when information technology, such as satellite imaging, allows detection of biodiversity 'hotspots' or areas of unacceptable

\footnotetext{
${ }^{2}$ In principle or at the project development stages, steps may be applied sequentially, but at implementation, one or more may be simultaneously applied.
} 
ratios of bycatch to target catch ${ }^{3}$, or skill and experience gained over time (learning-by-doing) of areas to avoid to reduce bycatch.

Minimization, one of the main tasks of conventional fisheries management, reduces the ongoing on-site impact of fisheries. Performance standards, such as individual catch and effort quotas, trip limits, Total Allowable Catch, and technology standards, such as prescribed gear and operating standards, are the primary means of minimization under direct or 'command-andcontrol' regulation. Bycatch-reducing technological change also minimizes bycatch and postbycatch mortality. Examples include: circle hooks that replaced J hooks and mackerel-type bait that replaced squid for pelagic longlines harvesting swordfish; Tori lines to minimize seabird bycatch on longliners; Turtle Excluder Devices for shrimp trawls; and sorting grids and altered mesh sizes and designs for groundfish trawls.

Restoration or rebuilding of a stock is necessary and mandatory when overfishing or depletion has reduced the stock to or below the minimum authorized by the LOSC (i.e. the MSY level) and, a fortiori, the minimum safe biological limit below which the species reproduction is threatened (according to the LOSC and Convention on Biological Diversity or CBD). They aim at halting and reversing negative trends and rebuilding stocks of target and non-target resources as well as critical habitats. Conventional fisheries conservation measures are used, coordinated in rebuilding plans, e.g. reduction of capacity, effort or removals, as a priority; restocking (introductions of reared juveniles); habitat restoration; and technological change, just as in the preceding steps but more stringently due to higher risk of collapse. More specific measures may

3 For example, acoustic devices on buoys attached to Floating Aggregator Devices (FADs) detect unacceptable bycatch levels under FADs, signaling tropical tuna purse seiners to avoid setting the net. 
be used under deep depletion, well below the MSY level, including no-take-zones, moratoria and international trade controls (Convention on International Trade in Endangered Species listing).

Least-cost implementation of the BIMH yields bycatch reduction per dollar expended less than that achieved by direct regulation $[13,15,19,20]$. By imposing the same standards upon all vessels and bycatch reduction channels within and across the BIM steps, irrespective of their specific level of bycatch, avoidance, minimization, and restoration methods and costs, direct regulation imposes a uniform 'one-size-fits-all' approach. Direct regulation faces diminishing returns in effectiveness, does not incentivize vessels to use all bycatch reduction channels across and within BIMH steps, and can face increasing amounts of foregone target catches and revenues (opportunity costs) per dollar expended in mitigation. Direct regulation increases the average cost of continued 'dirty' production of target species, creating a crude incentive to reduce bycatch through reducing the scale of production of both catch and bycatch. But because remaining (residual) bycatch is not given a price and cost, so that vessels do not bear the full social-ecological costs of fishing, the scale of production of both bycatch and target catch and the ratio of bycatch to target catch do not decline to the optimum.

Least-cost application of the BIMH intends to achieve the maximum possible bycatch reduction for a limited budget $[13,15,19,20]$. In principle, it results in the incremental cost from the last unit of bycatch reduction (the marginal cost) to equalize across and within BIMH steps. In practice, however, the average cost per unit of bycatch reduction is typically equated.

Incentive-based policy instruments, which price bycatch, are increasingly used to avoid and minimize bycatch and restore bycatch stocks in a least-cost way $[5,7,8,13,15,16,17,19,20]$. Instruments, such as fishing rights for bycatch, effort or capacity caps, bycatch credits, assurance 
bonds, and bycatch taxes, could be combined and progressively stacked to incentivize the BIMH, making it least-cost (cost-effective) $[13,15,19,20]$.

One of the most promising avenues is through incentivizing real-time spatial management (dynamic ocean management) [9]. For example, bycatch credits in the Eastern Bering Sea Pollock fishery incentivize real-time spatial management to avoid salmon bycatch [14]. They price and thereby increase the cost of residual bycatch and hence target species cost. The increased cost incentivizes producers to reduce the bycatch to target catch ratio and to reduce effort and hence catch of both bycatch and target species.

\section{Mitigation Hierarchy and Compensation}

Compensation, the fourth step of the BIMH, is used when a residual impact cannot be further reduced or restored and uses compensatory offsets [1,2,21]. This section discusses compensatory offsets' potential role in marine fisheries, where their application is complicated by co-existence of the LOSC and CBD.

The LOSC framework requires managing all target fishery stocks to maintain or restore populations of harvested species at levels which can produce the maximum sustainable yield [MSY], as qualified by relevant environmental and economic factors (Article 61.3). This paper argues that the LOSC, the UN Fish Stocks Agreement, and FAO Code of Conduct for Responsible Fisheries do not foresee compensatory offsets, applied elsewhere (off-site) on some other stock or meta-population (out-of-kind), even for the same species, for rebuilding depleted target stocks that all should be maintained or rebuilt at MSY (as NNL level) $[19,20]$. The LOSC also requires maintaining or restoring populations [of dependent and associated species] above levels at which their reproduction may become seriously threatened (Article 5e) without further specification. For these species, the MSY norm may not be relevant, but a No Net Loss level is 
nonetheless de facto defined, based on a reproduction criterion, above which all such stocks must be maintained. For living habitats, only the general environmental provisions calling to protect and preserve the marine environment (Article 192) may be used, a priori allowing any management measure, including presumably offsets.

The CBD must be implemented consistent with the LOSC (Art. 22.2). It stresses inter alia the need for maintenance and recovery of viable populations (Preamble, emphasis added) and defines sustainable use as a use that avoids long-term declines. Article $8 \mathrm{~g}$ provides that Parties shall rehabilitate and restore degraded ecosystem and promote the recovery of threatened species. The Convention stresses the need to avoid or minimize adverse impacts on ecosystem services, structure and functions as well as other components of ecosystems (Article 14 of the CBD; Addis Ababa Principle $\mathrm{N}^{\circ}$ 5). Compensatory offsets ${ }^{4}$ are clearly contemplated in its Resource Mobilization Strategy (United Nations Environmental Programme/CBD 2008) and in Decision XII/13, §38c, of CDB CoP 12 [United Nations Environmental Programme/CBD 2014]. In fisheries management, this would allow their use in BIMH step 4 for species for which the MSY norm is not relevant, such as non-aquatic species (seabirds, snakes, crocodiles), marine species of no interest to fisheries, protected species (e.g. turtles, precious corals, sharks, mammals); or living habitats (e.g. tropical corals, seagrass beds).

\footnotetext{
${ }^{4}$ Compensation is often narrowly limited to compensatory offsets, but it really covers a wide range of outcomes, including: (i) partial compensation (for Reduced Net Loss), (ii) full compensation (for No Net Loss); and (iii) overcompensation (for Net Gain) [1, 2, 21]. Outcomes (ii) or (iii) are mandatory for compensatory offsets, provided "off-site" and "out-of-kind", against residual biodiversity loss.
} 
This paper argues below that another type of offset, conservatory offsets, applies to fisheries for both target and non-target species.

\section{Conservatory Offsets in Fisheries}

Conservatory offsets are conservation actions taken off-site but in-kind in the first three BIMH steps, often at the impact's off-site origin, to reduce the impact, albeit indirectly. They are offsets because they are obtained off-site, away, and sometimes very far from the bycatch impact area (on-site fishing ground), e.g. for species with extensive migrations $[5,15,19,20]$. Conservatory offsets are in-kind, because they are applied to the same stock or meta-population of the target and non-target species.

They can be applied off-site e.g. to protect sea turtle nesting sites, sea bird rookeries, shark pupping grounds, or marine mammal breeding congregations, but also to reduce alternative sources of at-sea mortality, such as different fishing fleets (off-site) affecting the same species-stock (in-kind). They are incentive-based policy instruments, since their cost prices residual bycatch, which induces changes in producer (and consumer) behavior and decisionmaking in the first three BIHM steps. Over the long run, dynamic incentives induce or direct bycatch-reducing technological change. Although they are incentive-based policy instruments, they can also be induced by direct regulation or intrinsic motivation.

Early discussions of fisheries bycatch and offsets are found in Bellagio [3], Dutton and Squires [5], Janisse et al. [11], and Wilcox and Donlan [22]. Quigley and Harper [18] discuss salmon habitat offsets. Van Dover et al. [22] discuss deep-sea corals and chemosynthetic ecosystems and ecological restoration. None place these offsets within the BIMH conservatory part or explicitly distinguished them from compensatory offsets, although they discuss costeffectiveness (least-cost). 
Conservatory offsets are conservatory because, contrary to conventional offsets (fourth BIMH step), they are applied on the impacted population off-site, within its life cycle, to restore it, like all other 'conservatory' instruments used to avoid, minimize and restore biodiversity. They can substitute for policy actions taken to avoid, minimize, or restore biodiversity, allowing the substituted action to expand or contract to least-cost levels if need be. For example, conservatory offsets can provide gear that minimizes bycatch to another fishing fleet (off-site) either targeting the same bycatch species and stock (in-kind) or with bycatch on the same bycatch species and stock (in-kind). The reduced mortality in turn allows the on-site producers to reduce avoidance by fishing longer and satisfying overall bycatch targets. While conservatory offsets will substitute for actions to avoid or minimize biodiversity, they can complement another of the first three BIMH steps. For example, better post-bycatch handling practices to minimize bycatch mortality taken by the off-site fishing fleet not only allows the on-site producers to reduce avoidance by fishing more, but complement on-site bycatch minimizing gear and post-bycatch handling practices.

Conservatory offsets, by pricing bycatch, are incentive-based and least-cost, incentivizing all bycatch reduction channels across and within each step of the $\mathrm{BIMH}$, and induce equalized bycatch reduction per last dollar expended within and across the first three BIMH steps. Compensatory offsets, a form of direct regulation that is not least cost, address the residual from the fourth BIMH step after implementing the first three steps to the maximum extent practicable. This 'excessive' implementation creates diminishing returns rather than equating the additional mitigation cost per last unit mitigated across all bycatch reduction channels across and within BIMH steps. Compensatory offsets also treat the size, and perhaps design, of the offset as a direct function of the residual rather than the least-cost principle. 
Compensatory offsets are also strictly complementary to the policy instruments used in the first three BIMH steps. ${ }_{-}$

Conservatory offsets correspond to the 'Polluter Pays Principle' in that the party inflicting bycatch is responsible for paying or otherwise compensating for it (strict rather than negligence liability). ${ }^{6}$ The inflicting party has a Willingness to Pay to the affected party (other right holders, the State, etc.) that holds the right to no or reduced bycatch and the Willingness to Accept compensation. The Willingness to Pay by the party creating biodiversity loss and the Willingness to Accept compensation by the party with a right to no or reduced biodiversity loss bound the size of economically rational compensation for any voluntary or mandated offsets. Compensatory offsets, as direct regulation rather than voluntary, are not bound by these limits.

Conservatory offsets for bycatch of sea turtles, sea birds, sharks, marine mammals, and other species are in-kind, since they are for the stocks or meta-populations but in a different

${ }^{5}$ Both compensatory and conservatory offsets price and cost the bycatch (by the amount paid for the offsets). The price for conservatory offsets, however, incentivizes producers to implement the BIMH in a least-cost manner within and across steps in contrast to mandated compensatory offsets addressing only the BIMH residual. Their costs, and hence prices, will correspondingly differ, since they form under different circumstances and objectives.

${ }^{6} \mathrm{~A}$ tax could incentivize changes in producer and consumer behavior and the proceeds finance costs of conservatory offsets $[5,7,8,11,17,19,20,23]$. The tax is ideally levied on bycatch mortality (i.e. ratio between numbers killed through bycatch and total abundance), but can be levied on target species catch with a presumed average bycatch rate when the bycatch rate or mortality for the last unit of bycatch is unavailable. In principle, costs are shared among consumers, supply chain firms, and fishers (according to their ability to pass on costs). 
location within the stock's distribution range. Conservatory offsets can enhance production of eggs or juveniles of the adults affected by bycatch, in remote habitats, away from the fishing ground, that are critical for reproduction (e.g. turtle nesting beaches, seabird rookeries, shark pupping grounds, spawning grounds in general). They can therefore reduce the bycatch impact more least-cost than additional top-down regulations, reducing eggs' and juveniles' mortalities and not only the causal fishing mortality of adults. Conservatory offsets can also protect sources in meta-populations when the sinks are fished. Conservatory offsets are thus not only off-site as conservatory offsets -- but in-kind for sources that generate larval flows or recruitment to exploited sinks in meta-populations.

In terrestrial offsets for flora and fauna, gains are generally required to be located as close to the development/impact site as possible to ensure the highest possible degree of equivalence. However, with transboundary species distributed in Exclusive Economic Zones and the High Seas and fished in both areas, marine compensation needs to deal with particularly extended life cycles and ecosystems. Fortunately, the 1995 United Nations Fish Stocks Agreement requires compatible management measures across the entire distribution range of stocks, and this Principle of Compatibility should facilitate the international agreement required for conservatory offsets to succeed at such scale.

The conservation requirement of 'proximity' that makes sense when compensating for habitat damage on land, and could make sense in coastal areas (e.g. when dealing with coral reefs, seagrass beds, estuarine habitat) and some deep-water benthic habitat (e.g. cold water corals and sponges on demersal trawl grounds), makes less sense when dealing with compensation within the life cycle in the open ocean where the spatiotemporal characteristics of that life cycle are overriding and migrations may be extensive. The consequence is that if a fishery is wide ranging, or many different fisheries interact within the life cycle of the target 
species, it may be more difficult to determine who can provide the needed ecosystem services and receive compensation, unless the offsetting activity can be undertaken in specific areas (e.g. in well localized turtle nesting beaches) by identified providers (specific coastal communities).

\subsection{Critiques of Offsets that Address Fisheries Bycatch}

Several quarters delivered critiques of both compensatory and compensatory offsets for bycatch $[4,6,24]$ :

1. Reducing bycatch through conventional methods (e.g. gear selectivity) helps broad groups of impacted species, but offsets (whether compensatory or conservatory) aid only a select few.

2. Offsets fail to adequately address bycatch mortality of late-stage individuals (subadults and adults), the most pressing threats to most marine megafauna populations. Conservatory offsets are relevant only for populations of species (e.g. elasmobranchs and marine mammals) that have a terrestrial or coastal reproduction stage on which providers could intervene.

3. Implementation entails significant and logistical challenges. Rigid caps on fishing associated with the bycatch mortality of a species or population and a legal requirement for compensation when bycatch exceeds the bycatch cap are both required. Few fisheries have bycatch limits, since necessary information for bycatch populations on demographics, bycatch levels, impacts from introduced predators, and conservation benefits are unavailable and costly.

4. The best application of offsets is to species whose population would be deteriorating, even if no action was taken, since they provide clear conservation gains (i.e. 
additionality). ${ }^{7}$

5. Simply considering offsetting decreases in population size does not indicate whether the changes affect the ecosystem structure and function. Numerous No Net Loss issues need to be faced, including genetic diversity and population distribution, age, and genetic structure, which affect ecosystem functions and services, etc. No Net Loss might be applied not just to megafauna, but also be applied to other biodiversity components.

The paper argues that conservatory offsets circumvent these criticisms, because they are: in line with the LOSC; a voluntary, incentive-based policy instrument; are applied on the impacted population or meta-population itself (in-kind), even if off-site, and in the first three steps of the $\mathrm{BIMH}$, as conservatory, not compensatory measures; and least-cost. (Even compensatory offsets circumvent most of these critiques.)

Specific rebuttals include for critique number: (1) conventional methods have shown their limits, and in any case, offsets supplement, not replace, conventional measures; (3) bycatch caps and extensive demographic information are not necessarily preconditions for conservatory offsets any more than they are for any other conservatory policy instruments; (4) this overlooks the potential for net gain and fisheries with mandatory rebuilding rather than the maintenance of some status quo; (5) the need to have a broad approach to biodiversity conservation (e.g.

\footnotetext{
${ }^{7}$ Additionality occurs when an intervention has an effect when compared to a baseline of what would have happened without the intervention (counter-factual). For fisheries, the 'baseline' for management and the minimum international norm for rebuilding is the abundance at MSY or any higher level. If stocks are at MSY under conventional policy instruments, conservatory offsets are not needed unless the first can efficiently be reduced (for least cost) by introducing the second.
} 
through large-scale MPAs) does not preclude application of conservatory offsets for megafauna when advantageous. In addition, conservatory offsets do not aim at some agreed status quota No Net Loss but to rebuilding all stocks to their MSY level. A depleted stock must be rebuilt even if it appears to be stable.

Conservatory offsets support effective and efficient conservation; for example, sea turtle eggs are required to yield reproductively competent adults. From a least-cost and maximum bycatch reduction perspective, what counts is the cost per unit of a reproductively competent sea turtle. Bycatch impact reduction is assessed after eggs, juveniles, and adults are all converted to this same unit of account (using mortality rates as exchange rates), even if a sexually mature turtle has a higher reproductive value than eggs or juveniles viewed solely in biological terms. Conservatory offsets, just like any other policy instrument, ultimately depend upon whether conservation is more effective with or without them, i.e. compared to the counter-factual ('additionality').

\subsection{Examples of the BIMH, Conservatory Offsets, and Sea Turtles}

This section considers examples of sea turtle bycatch reduction within the $\mathrm{BIMH}$ and conservatory offsets as a least-cost policy instrument. First, the Hawaii shallow-set pelagic longline swordfish fishery has a bycatch of Pacific loggerhead and leatherback sea turtles [8]. These vessels initially used J-hooks baited with squid. Application of the U.S. Endangered Species Act in 2001 led to several direct regulations to halt and reverse negative trends and restore populations using conventional on-site fisheries management instruments, and in BIMH terms:

- Avoidance: In 2001, a three-year time-area fishing closure was implemented. After reopening in 2004 , the avoidance was reduced, closer to a least-cost level, through the real-time spatial 
management program TurtleWatch, that is on-stock, in-kind, essentially on-site, to avoid sea turtle "hot spots" [10].

- Minimization through: (i) a technology standard imposing the use of circle hooks and mackerel-type bait that reduced sea turtle interactions and post-hooking mortality; (ii) line cutters and de-hookers to minimize post-hooking mortality; (iii) industry-wide performance standard through bycatch limits on each species.

Second, the California drift gillnet fleet harvesting swordfish avoids bycatch of Western Pacific leatherback populations through a 2001 time-area closure of about 90 percent of the fishing ground north of Point Conception [11]. The closure was not complete, allowing limited fishing further south. Until a recent performance standard (bycatch cap) was imposed, there was no turtle bycatch minimization imposed, not even through technology standards. The California drift gillnet fleet, beginning in 2004, sponsored conservatory offsets as nesting site protection in Baja California, Mexico to mitigate Pacific turtle bycatch and help stave off avoidance through extensive time-area closure [11]. It was financed by a voluntary, lump sum tax.

Saving or replacing one sexually mature Western Pacific leatherback turtle costs US\$1 through conservatory offsets based on nesting site conservation, US\$18 through avoidance (time-area closures) in the Hawaii fishery, and US\$132 through avoidance (time-area closures) in the California drift gillnet fishery, even allowing for risk [8]. Conservatory offsets, through nesting site conservation, would therefore provide least-cost bycatch mitigation, and provide an alternative incentive-based policy instrument to help reduce costs of avoidance (e.g. direct regulation costs of administration and opportunity costs of foregone catch) by relaxing closures in the Hawaii and California fisheries. While this would lower the additional cost for reducing 
bycatch of one more sea turtle in the BIMH Step 1, it would not equal the additional cost of reducing bycatch of one more sea turtle from introducing conservatory offsets (rising from a cost of zero to some positive value). Nonetheless, it would come closer to equalizing these additional costs, lowering total bycatch reduction costs. Conservatory offsets are also performance rather than process oriented, and hence should create stronger incentives to reduce bycatch.

In the examples above, technology standards, applied through 'lumpy' all-or-nothing direct regulation, are already implemented for minimization, and cannot be adjusted to alter the additional cost of bycatch reduction for one more turtle. ${ }^{8}$ Conservatory offsets, on the contrary, can be adjusted as stock abundance, environment, markets, and technology change. They might result in No Net Loss or even Net Gain in the adult impacted population depending on the amount of reproduction enhancement achieved. Paradoxically, when effective, increases in turtle abundance, increasing the probability of both bycatch and the tax paid by fishers, create a perverse feedback loop and an opposite incentive. The problem might be resolved by making the tax proportional to the bycatch mortality rate (bycatch/population size) instead of straight number of animals caught.

\section{International Seafood Sustainability Foundation sea turtle conservatory offsets}

The International Seafood Sustainability Foundation (ISSF) implements the Bellagio Blueprint [3] through voluntary conservatory offsets to protect nesting sites or reduce bycatch from small-scale or artisanal fleets, predominately for the transboundary sea turtle bycatch species, loggerheads and leatherbacks. They partially compensate to achieve Reduced Net Loss

\footnotetext{
${ }^{8}$ In principle, conservatory offsets could substitute for technology standards to lower costs, but not in practice.
} 
by contributing to population restoration. Least (or lower) cost conservatory offsets counter the diminishing returns that arise within each step when following the BIMH on-site to the maximum extent practicable. They substitute for avoidance and some kinds of minimization (e.g. bycatch limits). Advantages in consumer markets and stock restoration incentivized them. Most are community-based conservation that creates indirect conservation incentives.

Tuna processors, through the ISSF, voluntarily assess landings of globally caught longline-caught tuna at US $\$ 1 /$ ton to fund conservatory offsets and partly for reasons of intrinsic motivation rather than solely as an incentive mechanism [12]. The tax is levied on supply chain firms (processors), but costs are spread to consumers and producers (fishers) as retail prices increase and demand affects the price vessels receive. The 'Polluter Pays Principle' applies, since the party adversely impacting biodiversity through bycatch pays. Tax proceeds are distributed approximately equal to target catch, at $25 \%$ each for the Atlantic, Indian, Eastern Pacific, and Western and Central Pacific Oceans. The Ocean Foundation disburses all funds. Past and current ISSF conservatory offsets are discussed next.

\subsection{Western and Central Pacific Ocean: Leatherback conservation in Bird's Head region, Papua} Barat, Indonesia.

The Bird's Head region of Papua Barat hosts ca. $70 \%$ of leatherback nesting in the Western Pacific, also the source of turtles bycaught in the Western and Central Pacific Ocean international longline and the California drift gillnet fleets. Widespread failure of hatchling production on the nesting beaches was identified as a key factor contributing to the population decline. Since 2010, ISSF has supported the State University of Papua, the local lead institution for leatherback research and conservation in Papua-Barat. State University of Papua manages agreements established with three different communities at Bird's Head to engage in 
conservation at key nesting sites they own. Mitigation includes: (i) nest predation patrols; (ii) relocating "doomed" nests that, otherwise, would have been destroyed by high tides in safe areas above the high water mark; and (iii) applying in-situ nest protection at beaches throughout the year during peak nesting at the different sites. Other projects include trapping pigs (primary nest predator), installing barriers to protect nests from predation, two methods to mitigate threats from elevated sand temperatures for in-situ nests, and information programs such as outreach at four Mandopi village elementary schools in Manokwari (closest city to the nesting beaches where turtle meat and eggs are still sold).

ISSF supports the State University of Papua's program to develop innovative approaches to engage the beach owners' and their tenant communities as conservation partners, critical to long-term continuity of the nesting beach conservation actions. This includes providing community services at local villages. State University of Papua community workers and students offer agricultural extension workshops, teach elementary school children, and tutor math, reading, and personal hygiene in after-school programs that also groups take children to witness nesting leatherbacks, release hatchlings, learn about leatherback ecology and conservation, and participate in group activities. The State University of Papua team is moving towards comanagement with the Wau community within the Collaborative Forum established in 2014 to facilitate stakeholder involvement and resolve disputes. Co-management includes regular monitoring and capacity building of community members and staff from newly created local and provincial government entities. Urban outreach activities will expand to more schools and communities near Manokwari.

\subsection{Eastern Pacific Ocean: Hawksbill conservation in Nicaragua}


The ISSF funded the Eastern Pacific Hawksbill Initiative (ICAPO) since 2010 to conserve hawksbill turtles and nests at Estero Padre Ramos in Nicaragua and Bahia Jiquilisco in El Salvador, where more than $80 \%$ of each season's hawksbill nests in the Eastern Pacific Ocean are laid. Prior to this program, $100 \%$ of nests at both sites were collected for consumption or sale, and the hawksbill turtle was considered functionally extinct in the eastern Pacific. The project has become a model for community-based conservation in the region; the Eastern Pacific Hawksbill Initiative has engaged community members who move eggs from over $98 \%$ of the nests laid to a protected hatchery. Since the programs' start, a combined total of $>3,000$ nests have been protected, leading to release of $>300,000$ hatchlings. The Initiative also helped communities to establish an ecotourism program that recruits participants who pay a fee to assist in hawksbill conservation activities, while receiving food and lodging from local families. Since 2015, ISSF funds allowed the Initiative to engage with local fishers to find methods to reduce the considerable hawksbill bycatch in artisanal lobster gillnet fisheries.

\subsection{Eastern Pacific Ocean: Prevention and Reduction of Marine Turtle Fishery Bycatch in Peru} and Chile

This project addresses coastal longline and California drift gillnet sea turtle bycatch (notably leatherback). Asociacion Pro-Delphinus and Pacifico Laud operate a high frequency radio from fixed base stations along the coast of Peru to communicate with fishers at-sea in real time, thereby implementing real-time spatial management (avoidance). Twenty-five project ports extend over 3,500 km from Manta, Ecuador to San Antonio, Chile. Radio Conservation has disbursed information on marine endangered fauna, including marine turtles, to over 3,000 fishers. Workshops train fishers on safe handling and release of bycatch turtles (minimization). Pacifico Laud partnered with two fishing cooperatives to implement gear modification trials (LED illumination and acoustic deterrent devices - minimization) during the 2015 fishing season (June 
- November) for the Chilean drift gillnet swordfish fishery, and this effort began scaling up in 2017 as a result of interest from other cooperatives and the Chilean government.

5.4. Eastern Pacific Ocean: Ocean Leaders: Empowering young people from urban and diverse backgrounds to become tomorrow's leaders in fisheries science, fisheries management, and conservation.

Initially funded by ISSF in 2012, Ocean Discovery Institute involves U.S. urban students and a local fishing community in Baja California, Mexico with research and conservation to reduce sea turtle bycatch in coastal drift gillnet and longline fisheries. ${ }^{9}$ Students work with practicing scientists at government and academic institutions. Since 2014, students participated with local community members on: fieldwork in Baja California; data analysis; and poster and oral presentations at conferences, scientific meetings, and at the Report to the Community, an August special annual event.

5.5. Indian Ocean: Monitoring and conservation of sea turtles in the Andaman and Nicobar Islands

\footnotetext{
${ }^{9}$ These are essentially information programs. Information programs can address the insufficient information held by consumers compared to vessels and firms in the supply chain (asymmetric information externality in markets), which is not the case here. Information programs can also change intrinsic motivation, such as developing social norms of conservation, the case here. Either way, off-site information campaigns substitute for the producers of concern's on-site avoidance and minimization. Information programs in markets addressing the information externality linked to the bycatch externality constitute conservatory offsets.
} 
Since initial ISSF funding in 2011, the Dakshin Foundation established camps at remote nesting sites on Little Andaman and Greater Nicobar Islands to focus on conserving leatherbacks that interact with larger scale pelagic longline fisheries. Prior to this project, monitoring had ceased, even though it is the most important known Indian Ocean leatherback nesting site.

Monitoring camps and regular beach patrols ensure no disturbances or poaching on nesting sites. Surveys since 2015 were critical in understanding the post-tsunami status of nesting leatherbacks and in reviving long-term monitoring camps on Great Nicobar Island. Annual monitoring on Andaman Island shows a steady increase in nesting after poor nesting reported following the 2004 tsunami. The main Cuthbert Bay site manages olive ridley hatcheries, protects leatherbacks, and runs an Interpretative Center.

\subsection{Indian Ocean: Community based sea turtle conservation in Tanzania.}

Since 2012, Sea Sense worked closely with community-based groups known as Beach Management Units (BMUs), which are key fisheries stakeholders for fisheries planning, management, conservation, and development. Sea Sense works closely with BMUs in Temeke District, which has legal responsibility for their locality's fisheries management. Sea Sense's training and capacity building workshops for BMU members focused on increasing understanding of sea turtles in the wider marine ecosystem and impacts of fisheries interactions on their survival (avoidance and minimization). Species include loggerheads.

Three BMUs with a shared fishing ground combined to form a Collaborative Fisheries Management Unit that Sea Sense has helped train to develop fisheries resource action plans incorporating sea turtle conservation. It worked with community Conservation Officers in Temeke District to collect information and identify high-risk areas ('hotspots') for sea turtles from fisheries interactions (avoidance) to focus their subsequent outreach activities. 
Since 2015, SeaSense has focused on building relationships between BMUs and gill net fishers to increase compliance with laws prohibiting the take of captured turtles (avoidance) and providing training on how to release entangled turtles from nets (minimization). Sea Sense conducts awareness and sensitization activities at migrant fisher camps, in collaboration with BMUs, to address the camps' high level of turtle meat consumption.

\subsection{Atlantic Ocean: Sea turtle conservation in Brazil.}

Proyecto Tamar protects nesting sites for five sea turtle species, including loggerheads and leatherbacks that constitute larger scale pelagic longline bycatch. Since 2010, ISSF has supported conservation of a key loggerhead nesting population at Praia do Forte on Brazil's Bahia coast. Each nesting season, a team of tartarugueiros (local fishermen hired by Tamar to patrol the beaches every day) work alongside biologists to monitor and protect loggerheads and their nests along $30 \mathrm{~km}$ of beach (minimization). More than $84 \%$ of nests remain in situ. The remaining nests, threatened by erosion or predation, are relocated to safe sections of the beach or to hatcheries. Since 2011, Tamar and the community has protected 400-600 nests and released $30,000-40,000$ hatchlings each nesting season.

Community outreach activities include training of local youth and rangers on sea turtle biology and conservation at the Praia do Forte station to help run the 'Tamarzinhos' Environmental Education Program and other activities at the Visitor Center, (e.g. the campaign 'Not Everything Caught in the Net is Fish' campaign since 2014), directed to local fishermen, and other programs directed toward summer tourists and visitors. Over 180,000 people, on average, annually visited the Visitor Center since 2011.

5.8. Atlantic Ocean: Mitigation of turtle meat consumption on Santiago Island, Cape Verde. 
The Cape Verde islands support one of the largest loggerhead nesting populations in the world, which is threatened by extensive exploitation for their meat and eggs. ISSF has supported the Cape Verde Sea Turtle Network 'Nha Terra' ('This land is my land') program to reduce the high level of illegal consumption of turtle meat on the main populated island of Santiago. The program consists of workshops, training, and outreach activities with communities, government officers and national media and compliments efforts on the more remote nesting beaches to monitor and protect turtles in what has become one of the highest conservation priorities for sea turtles in the Atlantic.

Since 2011, the Cape Verde Sea Turtle Network has partnered with media outlets to raise awareness during the turtle harvest season, and has partnered with a growing number of local restaurants and grass roots community groups to reduce turtle meat consumption. For example, an effort was initiated in 2015 with Associação Ambiental Caretta Caretta to identify three landing points for turtle meat in Santa Cruz and seven zones in Praia where turtle meat is sold on the black market. Since 2015, the Cape Verde Sea Turtle Network worked with the new government to enact legislation and raise awareness with the National Police to reduce illegal meat and egg consumption and trade.

\section{Concluding remarks}

The least-cost biodiversity impact mitigation hierarchy provides a comprehensive framework by which to address bycatch reduction, and more broadly biodiversity conservation, that is consistent with terrestrial conservation $[13,15,19,20]$. Incentive-based policy instruments facilitate least-cost bycatch reduction within this framework.

Conservatory offsets, as an incentive-based policy instrument, can potentially increase conservation efficiency at lower cost. This cost-effectiveness especially matters when 
conservation budgets are limited or stakeholder or public support for conservation is limited. Conservatory offsets can also be applied to address the inadequate information held by consumers and even supply chain firms for the in-kind species or habitat.

Their effectiveness and 'additionality' - just like compensatory offsets and all other policy instruments - cannot be empirically and statistically evaluated without comparison to a clear counter-factual, i.e. to what would have happened without the policy intervention that provides the control to the policy treatment. Structural modeling of sea turtle populations with and without conservatory offsets (or other policy instruments) provides a `second-best' alternative, but has yet to be conducted. Sea turtle delayed sexual maturity complicates any scientific, statistically valid assessment of policy interventions, such as conservatory offsets that protect nesting sites, because of the long time period required before any hatchlings mature to sexual competence and return to lay eggs. Nevertheless, these are necessary, albeit by themselves not sufficient, measures that require urgent enactment to prevent the imminent extinction of some populations (e.g. Pacific leatherbacks). 
[1] BBOP. Standards on biodiversity offsets. BBOP, Washington DC;2012. http://bbop.foresttrends.org/guidelines/Standard.pdf

[2] BBOP. Updated Overview on Biodiversity Offsets. Business and Biodiversity Offsets Programme (BBOP). Forest Trends, Washington,DC;2013. http://www.foresttrends.org/documents/files/doc_3319.pdf

[3] Bellagio Blueprint for Action on Pacific Sea Turtles. Penang: WorldFish Center (2004) In P Dutton, D Squires, M Ahmed, editors. Conservation of Pacific Sea Turtles. Honolulu:University of Hawaii Press;2011.

[4] Doak D, Bakker V, Finkelstein M, Sullivan B, Lewison R, et al. Compensatory mitigation for marine bycatch will do harm, not good. Frontiers in Ecology and the Environment 2007;5:350-351.

[5] Dutton, P, Squires S. A holistic strategy for Pacific sea turtle recovery. Ocean Development and International Law 2008;39(2):200-222.

[6] Finkelstein, M, Bakker V, Doak DF, B. Sullivan, Lewison R, Satterthwaite WH, PMcIntyre PB, Wolf S, Priddel D, Arnold JM, Henry RW, Sievert P, Croxall J. Evaluating the potential effectiveness of compensatory mitigation strategies for marine bycatch. PLOS ONE 2008;3(6):e2480.

[7] Gjertsen H, Hall M, Squires D. Incentives to address bycatch. In Allen R, Joseph J, Squires D, editors. Conservation and Management of Transnational Tuna Fisheries. Ames, lowa: Wiley-Blackwell;2010.

[8] Gjertsen H, Squires D, Dutton PH, Eguchi T. Cost-effectiveness of alternative conservation strategies with application to the Pacific Leatherback Turtle. Conservation Biology 2014;28(1):140-149.

[9] Hobday, AJ, Hartmann K. Near real-time spatial management based on habitat predictions for a longline bycatch species. Fisheries Management and Ecology 2006;13:365-380.

[10] Howell EA, Hoover A, Benson SR, Bailey H, Polovina JJ, Seminoff JA, Dutton PH. Enhancing the TurtleWatch product for leatherback sea turtles, a dynamic habitat model for ecosystem-based management. Fisheries Oceanography 24(1):57-68;2015.

[11] Janisse C, Squires D, Seminoff J, Dutton PH. Conservation investments and mitigation: The California Drift Gillnet Fishery and Pacific sea turtles. In Grafton RQ, Hilborn R, Squires D, Tait N, Williams M, editors. Handbook of Marine Fisheries Conservation and Management. Oxford:Oxford University Press;2010.

[12] ISSF (International Seafood Sustainability Foundation) Progress summary of 2014-15 ISSF funded marine turtle projects. International Seafood Sustainability Foundation, Washington,D.C.;2016

[13] Lent R, Squires D. Reducing marine mammal bycatch in global fisheries: An economics approach. Deep Sea Research II 2017;140:268-277. 
[14] Little AS, Needle CL, Hilborn R, Holland DS, Marshall CT. Real-time spatial management approaches to reduce bycatch and discards: experiences from Europe and the United States. Fish ad Fisheries 2015;16(4):576-602.

[15] Milner-Gulland EJ, Garcia S, Arlidge W, Bull J, Charles T, Dagorn L, Fordham S, Graf Zivin J, Hall M, Schrader J, Vestergaard N, Squires D. Translating the terrestrial mitigation hierarchy to marine megafauna bycatch. Fish and Fisheries;In press.

[16] Pascoe S, Innes J, Holland D, Finas M, Thebaud O, Townsend R, Sanchirico J, Arnason R, Wilcox C, Hutton T. Use of incentive-based management systems to limit bycatch and discarding. International Review of Environmental and Resource Economics 2010;4:123161.

[17] Pascoe S, Wilcox C, Donlan CJ. Biodiversity offsets: A cost-effective interim solution to seabird bycatch in fisheries? PLoS ONE 2011;6(10): e25762.

[18] Quigley J, Harper D. Compliance with Canada's Fisheries Act: A field audit of habitat compensation projects. Environmental Management 2006;37(3):336-350.

[19] Squires D, Garcia SM, editors. Ecosystem-Level Impacts of Fisheries Bycatch on Marine Megafauna: Biodiversity Conservation through Mitigation, Policy, Economic Instruments, and Technical Change. Report of IUCN-CEM-FEG Scientific Workshop, Gland, Switzerland, 7-10 October 2013. Gland, IUCN;2014. http://ebcd.org/wpcontent/uploads/2014/11/353-Squires_et_Garcia-2014_Mitigating_ecosystem_level_impacts_of_bycatch-FEG_Meeting_report.pdf.

[20] Squires D, Garcia SM Fisheries Bycatch in Marine Ecosystems: Policy, Economic Instruments and Technical Change, IUCN Fisheries Experts Group, Gland, Switzerland;2015.

[21] ten Kate K, Crowe M. Biodiversity offsets: Policy options for governments. An input paper for the IUCN Technical Study Group on Biodiversity Offsets. Gland, Switzerland: IUCN;2014.

[22] Van Dover CL, Aronson J, Pendleton L, Smith S, Arnaud-Haond S, Moreno-Mateos D, Barbier E, Billett D, Bowers K, Danovaro R, Edwards A, Kellert S, Morato T, Pollard E, Rogers A, Warner R. Ecological restoration in the deep sea: Desiderata. Marine Policy 2014;44:98106.

[23] Wilcox C, Donlan CJ. Compensatory mitigation as a solution to fisheries bycatch-biodiversity conservation conflicts. Frontiers in Ecology and the Environment 2007;5:325-331.

[24] Zydelis R, Wallace BP, Gilman EL, Werner TB. Conservation of marine megafana through minimization of fisheries bycatch. Conservation Biology 2008;23(3):608-616. 


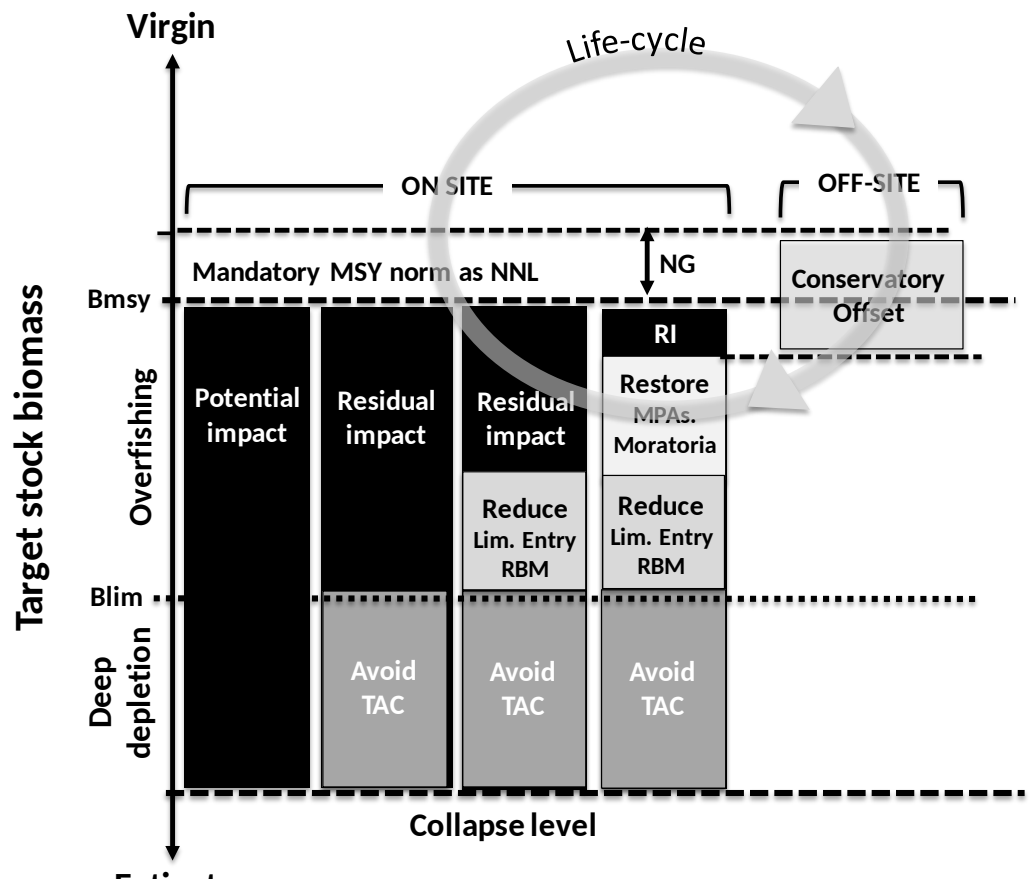

Extinct 
Figure 1: BIM hierarchy as applied in fisheries management. Bmsy, Maximum Sustainable Yield Biomass, is the NNL biomass level imposed by the LOSC. Blim is a precautionary biomass limit. TACs, Limited Entry and Rights-Based Management (RBM) were introduced sequentially. Conservatory offsets are recent and applied offsite but within the life cycle. Modified after BBOP [1]. 